\title{
Bullying, Victimization, and Resiliency: An Introduction to the Special Issue
}

\author{
Robert Geffner ${ }^{1,2} \cdot$ Scarlett Yang ${ }^{1} \cdot$ Nanette Burton ${ }^{1}$ \\ Accepted: 26 January 2021 / Published online: 10 February 2021 \\ (C) The Author(s), under exclusive licence to Springer Nature Switzerland AG part of Springer Nature 2021
}

\begin{abstract}
This special issue focuses on bullying and victimization in young adults and factors that contribute to resiliency. The articles take into consideration cultural factors, gender, and trauma history. Several of the research studies illustrate the complexity of the factors involved in bullying and the traumatic effects of the victimization, and authors highlight targeted ways for intervention and prevention. This special issue also highlights some of the international work being conducted in these areas. The intention of this special issue is to stimulate discussion among researchers, policy makers and practitioners who are trying to reduce bullying and child maltreatment while empowering those who have been victimized. Additional research utilizing complex designs with community and school samples is still needed to address the factors involved in these situations.
\end{abstract}

Keywords Child abuse $\cdot$ Empowerment $\cdot$ Prevention $\cdot$ Post-traumatic stress disorder $\cdot$ Post-traumatic growth $\cdot$ Adverse childhood experiences

\section{Introduction}

The Special Issue on Bullying, Victimization and Resiliency was compiled to focus on bullying in youth, its effects on the victims, and factors involved in resiliency. This special issue is unique in that some of the new research was conducted in different countries that are not often cited in research, including Greece, Nigeria, India, and Peru. These studies focused on youth and young adults and the effects of bullying experiences on post-traumatic stress disorder (PTSD), suicidal ideation, depression, and anxiety. The first study (Andreou et al. 2021) found that females obtained higher scores of posttraumatic growth (PTG) after school bullying victimization. The greater the duration and severity of victimization, the greater the PTSD and then the PTG. Suggestions for implications for handling bullying behaviors in schools were presented. The second study in Africa found that suicidal ideation was a symptom of bullying but that social support moderated

Robert Geffner

bgeffner@alliant.edu

1 Institute on Violence, Abuse and Trauma, 10065 Old Grove Road, \#101, San Diego, CA 92131, USA

2 Alliant International University, San Diego, CA, USA this relationship (Eze et al. 2021). Thus, the more social support that can be provided to bullying victims, the more resilience they may be able to develop to reduce the trauma and depression from the victimization. The third study in Peru by Levey et al. (2021) focused on resiliency and tested the psychometric properties of a resiliency scale. Their factor analysis suggested two factors related to resiliency, one positively associated with school attendance, financial hardship, and history of child abuse, and one negatively associated with household dysfunction, depression, anxiety, and sleep quality.

Two other articles also looked at issues in different cultural groups. Bhattacharyya et al. (2021) studied adolescents in India and found that culture strongly influences disclosure of abusive and victimization experiences. They also found that the process is much more complicated than a simple relationship between the severity of the abuse and the reluctance to disclose.. The authors found the relationship was is moderated by the perception of the victims of the severity of the abuse and a reluctance to disclose as a result of the increased potency of the emotional reactions to the abuse. Hicks et al. (2021) studied Black children and youth in the United States to determine the impact of adverse childhood experiences (ACEs) on developmental processes. Again, the increase in ACEs, the more symptomology, which has been found in numerous other research studies as well. They also looked at mediators and found that ACEs not only 
predicted depressive symptoms, but that these symptoms predicted substance abuse and later delinquency. The level of traumatic symptoms also mediated the association among ACEs, substance use and delinquency.

The current research is indeed focusing more on complex interactions and looking at mediating and moderating factors in the internalizing and externalizing effects of victimization in youth. Another study also involved the relationship between ACEs and resilience. As above, the higher the ACEs score the more trauma symptomology. Goldenson et al. (2021) found that a score of 4 seemed to be a major cut-off for more severe effects, and the lower the ACEs score, the more resilient the youth were to the distress. These youth reported less depression and somatization and it appears these effects continue as the youth get older. Jenkins et al. (2021) studied college students with a history of bullying and childhood trauma earlier in their lives and their selfreported victimization in college. They found that both direct and indirect exposure to abusive experiences in childhood was associated with later negative social experiences. However, they also found that internalizing difficulties was a mediator in the indirect experiences but did not mediate the effects of the direct experiences. Thus, more complex interactions appear to be more common in these situations, and a key factor is internalizing versus externalizing reactions to the abuse.

Tanzer et al. (2021) also studied the link between internalizing symptoms with respect to the severity of the childhood abuse. They found a positive link among childhood neglect, internalizing symptoms, and self-blame. This was an interesting study because it used a community sample. The results suggest that any interventions should target self-blame and internalizing symptoms. It appears that these types of symptoms may be affecting girls even more than boys. Stanley and Boel-Studt (2021) studied gender and complex trauma issues with regard to treatment in a residential care treatment program. They found gender effects with respect to the length of care for these complex trauma cases such that girls showed less change in functional impairment than boys with longer stays. These interaction effects of gender are important for both symptomologies resulting from abusive experiences as well as treatment outcomes. Longobardi et al. (2021) focused on body image in girls with respect to online sexual victimization. The poorer the body image of the girls, the higher the risk for online sexual victimization and other online risky behaviors. Sexting and exhibitionism were not mediating factors here even though it was expected.

Since disclosure does not occur often and there are several factors that reduce the likelihood of youth reporting these types of victimization, Fernet et al. (2021) wanted to focus more on the help-seeking process regarding dating violence in youth. Their qualitative study indicated that these youth were reluctant to disclose, but if they did, the disclosure was more likely to peer confidants they trusted, who would not likely judge them, and who would validate their interpretation of the experiences. Thus, peer support groups may have more influence on disclosure than professionals in the field.

Two articles then focused on interventions for youth who have trauma histories. The first one described an innovative culturally-based program, the Tree of Life, that was being proposed for use with refugees and immigrants in Canada, United States, United Kingdom, and South Africa (Stiles et al. 2021). The goal is to use a culturally-based trauma-informed intervention for a highly traumatized and difficult population where very limited evidence-based programs exists. The design of the research is described in this article, as well as the interventions itself. The second article involves an evaluation of a child maltreatment curriculum for high school students (Diaz et al. 2021). This is a unique pilot study because it is geared to high school students, whereas most other programs focus on younger students. This preliminary study showed that high school students who received the prevention curriculum increased their identification and knowledge of safety-related resistance strategies. This is a good first step to providing prevention programs throughout educational levels, but still lacking is the research to indicate whether the knowledge of safety techniques converts to actual behaviors that empower the students. Another study did focus on students' active versus passive bystander intervention when confronted by other students' bullying behaviors. Chapin and Stern (2021) obtained information from youth in a survey of various types of bullying behaviors that they committed or observed and also the parenting styles in their home. They found that even though certain students with authoritarian parents said they were more likely to intervene in such situations, they were least likely to actually do so. Those with authoritarian or permissive parents showed the opposite pattern of intervening even though both groups of students had no significant differences in their intent. These studies provide some key factors to consider when developing intervention and prevention programs.

Thus, this special issue targets several studies that illustrate the complexity of the factors involved in bullying and victimization effects and ways for intervention and prevention. More complex designs that include various factors, including gender and child development issues, are needed to be able to determine the interaction effects and predictability of various factors. The special issue ends with a Commentary by Wikenius (2021) concerning possible biological resilience. This commentary describes biological mechanisms that may be involved in childhood adversities, and these biological mechanisms may then influence the effects of child abuse and neglect. These then that may lead to resilience. The epigenetic view is quite controversial in the field of child maltreatment and ACEs, but it is gathering more attention recently. This special issue will hopefully stimulate discussion among researchers and practitioners who are trying 
to reduce bullying and child maltreatment while empowering those who have been victimized. Additional research utilizing complex designs with community and school samples is still needed to address the factors involved in these situations.

\section{References}

Andreou, E., Tsermentseli, S., Anastasiou, O., \& Kouklari, E. C. (2021). Retrospective accounts of bullying victimization at school: Associations with post-traumatic stress disorder symptoms and post-traumatic growth among university students. Journal of Child and Adolescent Trauma. https://doi.org/10.1007/s40653-02000302-4

Bhattacharyya, A., Lev-Wiesel, R., \& Banerjee, M. (2021). Roles of emotional reactions and potency in coping with abusive experiences of Indian adolescent. Journal of Child and Adolescent Trauma. https://doi.org/10.1007/s40653-020-00312-2

Chapin, J., \& Stern, A. (2021). Upstander intervention and parenting styles. Journal of Child and Adolescent Trauma. https://doi.org/10. 1007/s40653-019-00287-9

Diaz, M, J., Wolfersteig, W., Moreland, D., Yoder, G., Dustman, P., \& Harthun, M. L. (2021). Teaching youth to resist abuse: Evaluation of a strengths-based child maltreatment curriculum for high school students. Journal of Child and Adolescent Trauma. https://doi.org/ 10.1007/s40653-020-00304-2

Eze, J, E., Chukwuorji, J, C., Ettu, P, C., Zacchaeus, E, A., Iorfa, S, K., \& Nwonyi, S, K. (2021). Bullying and suicide ideation: Testing the buffering hypothesis of social support in a sub-Saharan African sample. Journal of Child and Adolescent Trauma. https://doi.org/ 10.1007/s40653-019-00294-w

Fernet, M., Désilets, L., Hébert, M., \& Cousineau, M, M. (2021). Informal help-seeking process regarding romantic issues and dating violence: A qualitative study. Journal of Child and Adolescent Trauma. https://doi.org/10.1007/s40653-019-00289-7

Goldenson, J., Kitollari, I., \& Lehman, F. (2021). The relationship between ACEs, trauma-related psychopathology and resilience in vulnerable youth: Implications for screening and treatment. Journal of
Child and Adolescent Trauma. https://doi.org/10.1007/s40653-02000308-y

Hicks, M, R., Kernsmith, P., \& Smith-Darden, J. (2021). The effects of adverse childhood experiences on internalizing and externalizing behaviors among black children and youth. Journal of Child and Adolescent Trauma. https://doi.org/10.1007/s40653-020-00316-y

Jenkins, L., McNeal, T., Drayer, J., \& Wang, Q. (2021). Childhood trauma history and negative social experiences in college. Journal of Child and Adolescent Trauma. https://doi.org/10.1007/s40653020-00315-Z

Levey, E, J., Rondon, M, B., Sanchez, S., Williams, M, A., \& Gelaye, B. (2021). Psychometric properties of the Spanish version of the 10item Connor Davidson resilience scale (CD-RISC) among adolescent mothers in Peru. Journal of Child and Adolescent Trauma. https://doi.org/10.1007/s40653-019-00295-9

Longobardi, C., Fabris, M, A., Prino, L, E., \& Settanni, M. (2021). The role of body image concerns in online sexual victimization among female adolescents: The mediating effect of risky online behaviors. Journal of Child and Adolescent Trauma. https://doi.org/10.1007/ s40653-020-00301-5

Stanley, L, H, K., \& Boel-Studt, S. (2021). The influence of youth gender and complex trauma on the relation between treatment conditions and outcomes in therapeutic residential care. Journal of Child and Adolescent Trauma. https://doi.org/10.1007/s40653-019-00285-x

Stiles, D, A., Alaraudanjoki, E., Wilkinson, L, R., Ritchie, K, L., \& Brown, K, A. (2021). Researching the effectiveness of tree of life: An Imbeleko approach to counseling refugee youth. Journal of Child and Adolescent Trauma. https://doi.org/10.1007/s40653019-00286-w

Tanzer, M., Salaminios, G., Morosan, L., Campbell, C., \& Debbané, M. (2021). Self-blame mediates the link between childhood neglect experiences and internalizing symptoms in low-risk adolescents. Journal of Child and Adolescent Trauma. https://doi.org/10.1007/ s40653-020-00307-z

Wikenius, E. (2021). Can early life stress engender biological resilience? Journal of Child and Adolescent Trauma. https://doi.org/10.1007/ s40653-020-00303-3

Publisher's Note Springer Nature remains neutral with regard to jurisdictional claims in published maps and institutional affiliations. 